\title{
The fossil record of camelids demonstrates a late divergence between Bactrian camel and dromedary
}

\author{
Denis Geraads, Gilles Didier, Andrew Barr, Denne Reed, and Michel Laurin \\ Acta Palaeontologica Polonica 65 (2), 2020: 251-260 doi:https://doi.org/10.4202/app.00727.2020
}

A new compilation of the Old World fossil record of Camelidae and a recent phylogenetic analysis allow a new assessment of the timing of the clade's diversification. Using a recent implementation of the fossilized birth-death process, we show that the divergence between Bactrian camel and dromedary has a peak probability density around $1 \mathrm{Ma}$ and probably occurred less than 2 million years ago. These dates are much younger than molecular estimates, which place the divergence between the dromedary and the Bactrian camel between 4 and 8 million years ago. Calibration problems in molecular dating seem to explain much of this difference.

Key words: Mammalia, Camelidae, phylogeny, divergence time, fossil record, birth-and-death models, Pleistocene, Africa.

Denis Geraads [denis.geraads@mnhn.fr] and Michel Laurin [michel.laurin@mnhn.fr , ORCID ID 0000-0003-2974-9835] (corresponding author), CR2P-UMR 7207, CNRS, MNHN, UPMC, Sorbonne Université, CP 38, 8 rue Buffon, 75231 Paris Cedex 05, France. Gilles Didier [gilles.didier@umontpellier.fr], IMAG, Univ Montpellier, CNRS, Montpellier, France. W. Andrew Barr [wabarr@gwu.edu ], Center for the Advanced Study of Human Paleobiology, Department of Anthropology, The George Washington University, Washington DC 20052, USA. Denné Reed [reedd@austin.utexas.edu], Department of Anthropology, University of Texas at Austin. Austin, TX 78712, USA.

This is an open-access article distributed under the terms of the Creative Commons Attribution License (for details please see creativecommons.org), which permits unrestricted use, distribution, and reproduction in any medium, provided the original author and source are credited. 
Farf Full text $(252.9 \mathrm{kB})$

FoF 5 Supplementary file $(142.0 \mathrm{kB})$ 